\title{
mRNA Vaccine: How to Meet the Challenge of SARS-CoV-2
}

\author{
Yingqi Jin ${ }^{1 \dagger}$, Chen $\mathrm{Hou}^{1 \dagger}$, Yonghao $\mathrm{Li}^{1 \dagger}$, Kang Zheng ${ }^{2 *}$ and Chuan Wang ${ }^{1,3 *}$ \\ 1 Institute of Pathogenic Biology, Hengyang Medical College, University of South China, Hengyang, China, 2 Department of \\ Clinical Laboratory, Hengyang Central Hospital, Hengyang, China, ${ }^{3}$ Hunan Province Cooperative Innovation Center for \\ Molecular Target New Drug Study, University of South China, Hengyang, China
}

OPEN ACCESS

Edited by: Yongjun Sui,

National Cancer Institute (NIH), United States

Reviewed by: Jungang Chen,

University of Arkansas for Medical Sciences, United States Irina V. Kiseleva, Institute of Experimental Medicine (RAS), Russia

*Correspondence: Chuan Wang wangchuan@usc.edu.cn Kang Zheng

1031015796@qq.com

${ }^{\dagger}$ These authors have contributed equally to this work

Specialty section:

This article was submitted to Vaccines and Molecular Therapeutics, a section of the journal

Frontiers in Immunology

Received: 24 November 2021 Accepted: 27 December 2021

Published: 21 January 2022

Citation:

Jin Y, Hou C, Li Y, Zheng K and Wang C (2022) mRNA Vaccine: How to Meet the

Challenge of SARS-COV-2.

Front. Immunol. 12:821538. doi: 10.3389/fimmu.2021.821538
Coronavirus disease 2019 (COVID-19), caused by severe acute respiratory syndrome coronavirus 2 (SARS-CoV-2) with high infectivity, pathogenicity, and variability, is a global pandemic that severely affected public health and the world economy. The development of safe and effective vaccines is crucial to the prevention and control of an epidemic. As an emerging technology, mRNA vaccine is widely used for infectious disease prevention and control and has significant safety, efficacy, and high production. It has received support and funding from many pharmaceutical enterprises and becomes one of the main technologies for preventing COVID-19. This review introduces the current status of SARS-CoV-2 vaccines, specifically mRNA vaccines, focusing on the challenges of developing mRNA vaccines against SARS-CoV-2, and discusses the relevant strategies.

Keywords: SARS-CoV-2, COVID-19, mRNA vaccine, challenges, strategies

\section{INTRODUCTION}

Severe acute respiratory syndrome coronavirus 2 (SARS-CoV-2) is a novel positive-sense singlestranded RNA coronavirus, which belongs to the Betacoronavirus genus $(1,2)$. Coronavirus disease 2019 (COVID-19) caused by this virus has spread rapidly throughout the world $(3,4)$, threatening public health and the world economy. Globally, as of December 25 in 2021, more than 278 million confirmed cases of COVID-19, including more than 5 million deaths, have been reported to the World Health Organization (WHO) (5). According to the severity of the disease, COVID-19 is divided into different clinical classifications: asymptomatic, mild, moderate, severe, and critical symptoms $(3,6,7)$. Of note, SARS-CoV-2 has high transmission efficiency for asymptomatic or mild cases (8). The clinical symptoms of COVID-19 include fever, sore throat, dry cough, pneumonia symptoms (with or without hypoxemia), and so on. In addition, the complications of patients with COVID-19, such as acute respiratory distress syndrome, sepsis, acute liver and kidney injury, multisystem inflammatory syndrome, autoimmune hemolytic anemia, and neurological complications, are also worthy of attention (9).

The epidemiological studies of COVID-19 have demonstrated that airborne transmission is the major mode in the spread of SARS-CoV-2. Significantly, fecal-oral transmission and transplacental transmission are possible (10-12). On the other hand, SARS-CoV-2 can spread between humans and animals (13). Recent studies have suggested that severe COVID-19 is not limited to the elderly; children and young adults are also at risk $(14,15)$. Furthermore, the clinical characteristics vary with age. Altogether, SARS-CoV-2 has high infectivity, pathogenicity, and mutability, making the prevention and control of COVID-19 difficult. 
Vaccination is one of the most effective and economical ways to prevent and control infectious diseases. It is essential to develop safe and effective vaccines for implementing mass vaccination to prevent and control the COVID-19 pandemic. In recent years, mRNA vaccines have been studied extensively for the prophylaxis and control of infectious diseases (16-18). Compared with other vaccines like whole bacteria, subunit, and DNA vaccine, the mRNA vaccine can induce $\mathrm{T}$-cell and B-cell immune response and is non-integrating and naturally degradable (19-22). In addition, the fast and simple production procedures, free of eggs and cells, make the mRNA vaccine a promising and attractive vaccine candidate that potentially fills the gap between the emerging epidemic and the urgent need for effective vaccines (23). So far, it has been demonstrated that BNT162b2 (BioNTech/Pfizer) and mRNA1273 (Moderna), granted authorization for emergency use, are generally safe and efficacious to prevent COVID-19 (24-26).

Worldwide, despite the measures taken to control COVID-19 disease spread, infections still occur, suggesting that more effective vaccines will be an immediate need to end the pandemic. Here, we focus on the current challenges of the mRNA vaccine against SARS-CoV-2 and discuss possible countermeasures to contain the continuing spread of the disease.

\section{CHALLENGES}

With the continued global epidemic, the COVID-19 mRNA vaccines still face several important challenges: SARS-CoV-2 variants, protective immunity, immune evasion, vaccinated population, and adverse reactions after vaccination. Undoubtedly, more in-depth knowledge on these challenges will contribute to the design of safer and more effective mRNA vaccines in the future.

\subsection{Variants}

Generally, the RNA virus has a high mutation rate. In addition, all viruses, including SARS-CoV-2, may change over time (27, 28). Most changes have little impact on the properties of the virus. However, some changes may affect the properties of the virus reported to the $\mathrm{WHO}$, such as transmission capacity, related disease severity, or the performance of vaccines, therapeutic medicines, diagnostic tools, and so on (29). For SARS-CoV-2, multiple selective pressure may develop novel variants. It is considered that the most likely selective pressure is to increase the inherent adaptability of the virus by directly replicating within the host or spreading between the hosts (30, 31). In addition, variants may include mutations that change interactions with key host components (32). Of note, selective pressure can induce mutations that permit variants to escape from adaptive immune responses (30).

\subsubsection{Antibody Neutralization and Immune Evasion}

In the changing global SARS-CoV-2 pandemic context, several variants including B.1.1.7 (Alpha), B.1.351 (Beta), B.1.617.2 (Delta), etc. showed different sequence variations and amino acid sequence changes of the spike protein, which has been reported and has aroused wide concern due to their widespread transmission and possible immune evasion (33).

For the Lambda variant, the receptor-binding domain (RBD) mutation can weaken the ability to recognize broadly neutralizing antibodies. Mutations of T76I and L452Q induce higher infectiousness (34). Besides, the 7-amino-acid deletion within the $\mathrm{N}$-termini domain outside the RBD domain leads to immune evasion. Notably, antibodies from Pfizer-BioNTech vaccinated individuals drop about 3.5-fold for the Delta variant after 6 months (35). The Delta variants have the characteristics of several spike protein mutations, which may affect immune responses and vaccine potency, including T19R, $\Delta 157-158$, L452R, D950N, T478K, P681R, and D614G (36, 37). Significantly, SARS-CoV-2 strains with mutations at P681R may enhance viral replication, resulting in higher viral loads and increased spread (38). Also, laboratory data suggested that D614G substitution, which is prevalent among SARS-CoV-2 strains, improves the competitive fitness, infectivity, and transmission of the strains in primary human cells and animal models $(31,39)$. Besides, the reorganized receptor-binding interface of the Delta variant attenuates interactions with some neutralizing antibodies, resulting in immune evasion (36).

As an important strategy to control the COVID-19 pandemic, mRNA vaccination remains effective in preventing symptomatic and severe COVID-19 associated with infection from several variants. However, whether the effectiveness of mRNA vaccines will be reduced due to variants is still a concern. Using a TNCC (a test negative case control) analysis, the estimated vaccine effectiveness against symptomatic disease with Delta infection for two doses of BNT162b2 is approximately $88 \%$ (95\% CI, 85.3 to 90.1) (40). Due to concerns about thrombotic events after vaccination with ChAdOx1 nCov-19, heterologous mRNA boost strategies have been recommended and implemented $(41,42)$. Laboratory data have indicated that heterologous BNT162b2 boost after ChAdOx1 nCov-19 consistently leads to higher neutralizing titers against the Alpha, Gamma, and Beta variants compared with homologous BNT162b2 vaccination. Interestingly, homologous BNT162b2 prime boost seems to be more efficient in generating neutralizing antibodies against the Delta variant $(43,44)$. Similarly, it has been reported that an mRNA-1273 boost can induce the production of antibodies that neutralize the B.1.351 variant. In addition, mRNA-1273 vaccine can stimulate the SARS-CoV-2-specific memory B cell produced by the first dose of ChAdOx1 nCov-19 vaccine. Compared with a ChAdOx1 nCov-19 boost, an mRNA-1273 boost may provide better immune protection against the B.1.351 variant (45).

\subsubsection{Vaccine Breakthrough Infections}

The major factor of the vaccine breakthrough infections of variants may be obtaining new antigenic properties to circumvent the recognition of broadly neutralizing antibodies generated from vaccination, which may be enhanced by the weakening of immune protection of the vaccination over time (35). With the emergency and wide spread of variants and the occurrence of vaccine breakthrough infections, some studies have compared the protective efficiency of mRNA vaccines against SARS-CoV-2 variants of concern, assessing variant- 
specific viral loads or neutralizing antibodies in cases of vaccine breakthrough infections, to prevent and control the global SARSCoV-2 pandemic better $(46,47)$.

A case-to-case study, comparing the effectiveness of mRNA vaccines against Delta versus Alpha variants, has found higher infectivity with the Delta variant infections and significantly higher odds of vaccine breakthrough infections in Delta cases when compared with Alpha cases (47). Additionally, a multicenter retrospective cohort study of patients with B.1.617.2 infection showed that the odds of severe COVID-19 needing supplemental oxygen were significantly lower following vaccination compared with unvaccinated individuals in the vaccine breakthrough group (33). Interestingly, vaccinated and unvaccinated groups at diagnosis have similar PCR cycle threshold values, but viral loads declined faster in vaccinated patients.

Variants may cause adverse effects on protective efficacy of currently available mRNA vaccines. The emergence and transmission of variants present a grand challenge for the prevention and control of the SARS-CoV-2 pandemic via mRNA vaccination (48-50). Differences in the number of patients with variant infections, age, individuals receiving mRNA vaccines, follow-up of vaccinated individuals, sensitivity or specificity of PCR testing, and other aspects may have an impact on evaluating the effectiveness of mRNA vaccines (40). Therefore, study protocols and data collection assessing the effectiveness of mRNA vaccines should be carefully designed and implemented. Detecting the SARS-CoV-2 nucleic acid of patients and reviewing the existing variants on neutralizing antibodies are required to understand the transmissibility, infectivity, virulence, and immune escape of variants. Evaluating the effectiveness of current mRNA vaccines against SARS-CoV-2 will contribute to develop elaborate strategies for more effective mRNA vaccines against the COVID-19 pandemic.

\subsection{Protective Immunity}

Although much remains to be determined about immune-related factors that protect against SARS-CoV-2 infection, emerging data have demonstrated the importance of humoral and cellular immunity in terms of protection $(51,52)$. Therefore, it is important to ensure the development of effective mRNA COVID-19 vaccines.

Generally speaking, mRNA vaccines have the unique ability to induce the innate immune system to regulate antigen-specific immune responses. mRNA vaccines can be identified by MHC I and MHC II, which led to antigen-specific humoral and cellular immune responses (53). Meanwhile, it has adjuvant features which can timulate immune cells to secrete tumor necrosis factor- $\alpha$ (TNF- $\alpha$ ), interferon- $\alpha$ (IFN- $\alpha$ ), and other cytokines (CK) that activate the consuming adaptive immune responses (54). Besides, the mRNA vaccine produces high levels of virusblocking antibodies, known as neutralizing antibodies (nAb), so many scientists believe that it is superior to other vaccines in preventing infection (55). However, the results of several mRNA candidate vaccine studies show that mRNA may stimulate excessive immune response, which will stimulate cells to secrete large amounts of interferon, thereby inhibiting the effect of mRNA translation and ultimately leading to immune response termination $(56,57)$. In addition, there is currently a lack of information on the protective life span caused by mRNA vaccines. Effective measurements of vaccines and definitive experimental descriptions of duration do not yet exist. Experience with other human coronaviruses has shown that reinfection is possible due to reduced antibody response. Special attention must be paid to mRNA potential problems, which will help us use mRNA more effectively $(58,59)$.

In the absence of data for humans, animal studies can help to identify potential correlates of protection. However, there is still a lack of animal models that can fully simulate human immune responses, and animal studies cannot fully predict efficacy in humans (60). The results of H10N8 and H7N9 mRNA vaccines showed that mRNA vaccines could stimulate the human immune response to produce higher neutralizing antibodies, but the animal immune response could only produce lower neutralizing antibodies (21), which proved this point of view. Moreover, since SARS-CoV-2 is a novel pathogen, any surrogate endpoints identified in animal studies would ideally need validation in clinical trials. Researchers need to continue to seek clinical evidence of the effectiveness of mRNA vaccines in human studies (24).

\subsection{Vaccinated Population}

As we all know, the immune system is related to multiple factors which obviously have roles both in innate and adaptive immunity. The monitoring of protective immunity in different immunized populations with vaccination is one of the most important factors in the effectiveness of vaccine. The physical conditions of the recipient as well as sex and age also affect the effectiveness of vaccine.

SARS-CoV-2 is extremely infectious. Everyone can be considered a susceptible group, and the infected individuals present a variety of symptoms (61). Some initial observations have indicated that adults are more likely to contact SARS-CoV2 than children (62); however, limitation in testing availability in many countries during the pandemic has made it difficult to accurate quantify the true risk of infection in individuals. It is certain that patients with other clinical diseases may be more susceptible to infection (63). Recently, the WHO has shown that young people are becoming the main spreader of SARS-CoV-2, and people under 40 are more susceptible to infection, which will increase the risk of infection for the most vulnerable groups, especially the elderly and patients (64). Additional clinical trials are needed to better establish the infection rate of SARS-CoV-2.

Vaccines have made a huge contribution in preventing infection. It is crucial to understand the difference between the antibody response of different immune populations to vaccination and infection as soon as possible. Compared with traditional vaccines, there are unique advantages of the use of mRNA-based antiviral vaccines (65). The mRNA-based vaccines mRNA-1273 and BNT162b1 are two mRNA vaccines that are currently progressing rapidly. The phase 3 trial of mRNA-1273 (the fastest-growing mRNA vaccine currently in development, which stimulates the expression of a target antigen after vaccination) was launched in late July 2020. The trial was mainly for people who have no infection history at the age of 18 or older and included some persons with different racial and 
ethnic backgrounds. The results have shown that the safety of the mRNA- 1273 vaccine is $94.1 \%$ effective in preventing SARS-CoV-2 when an individual is completely vaccinated (25). Infection and the safety of mRNA-1273 are not affected by age (66). However, the trial did not precisely assess the immunogenicity of different populations, and pregnant women and children were not included in the trial. Additional evaluation of vaccines needs to be planned $(25,67)$. Consistent with mRNA-1273, the BNT162b2 vaccine showed $94 \%$ efficacy in preventing SARS-CoV-2 infection, while there is still controversy about the immunization effect in different populations $(68,69)$. Taken together, although the mRNA vaccine under development provides great hope for the prevention of COVID-19, there is still a lack of strong proof of the immune effect in different populations. More in-depth research should be conducted to understand the vaccination status in different people. Understanding the mechanisms involved in individual disparity in the effectiveness of mRNA vaccines will contribute to improve the development of mRNA vaccines.

\subsection{Adverse Reactions}

As of December 21, 2021, there are over 300 COVID-19 vaccine candidates being developed. Of these, at least 137 candidates derived from different platforms, including the whole-microbe approach (inactivated vaccine, live-attenuated vaccine, and viral vector vaccine), the subunit approach, and the genetic approach (nucleic acid vaccine), are currently in clinical development (70, 71). Like with any vaccine, mild to moderate side effects may emerge after being vaccinated against COVID-19 (72). It is a normal sign of the immune response of the body to the vaccine (73). However, severe side effects or adverse reactions could be experienced, causing fear and anxiety about vaccination in the population $(72,74)$. Therefore, evaluating safety is more conducive to the development and emergency use of COVID-19 vaccines.

Theoretically, mRNA vaccine has greater security compared with other types of vaccines, for instance, without infectious virus in the production process, a lower risk of virulence reversion, and insertional mutagenesis (75). Nevertheless, highquality real-world safety data on mRNA-based COVID-19 vaccines are still relatively scarce in the literature. Common adverse reactions to mRNA-based COVID-19 vaccines include allergic reaction and some other side effects such as arm pain, fatigue, and a mild fever (Table 1). Also, serious adverse reactions following BNT162b2 mRNA COVID-19 vaccination including pericarditis, arrhythmias, deep vein thrombosis, pulmonary embolism, myocardial infarction, intracranial hemorrhage, and thrombocytopenia need more emphasis (82) (Table 1). A study demonstrated a possible association between Bell's palsy and vaccination with BNT162b2 and mRNA-1273 COVID-19 mRNA vaccine (82). Regarding other mRNA vaccines like CVnCov, Arct-021, and LNP-nCovsaRNA, the main adverse reactions are mild (Table 1). Clinical trials may be inherently limited in assessing vaccine safety because of the small number of participants and the inadequate representation of the sample. Hence, long-term and comprehensive monitoring of vaccine safety is required.

We found an interesting fact that adverse reactions appear within different time periods after injection of some vaccines by data analysis. What could be the reason? Allergic reactions caused by vaccination are usually lgE-mediated and occurred within the first 30 min after vaccination (83). Not all immediate reactions associated with vaccines are true allergic reactions (84). The allergic reactions are usually related to vaccine components, which include excipients, inactive ingredients, and liposomal delivery vehicles $(84,85)$. The possibility that differential composition may make adverse events happen at different temporal stages after vaccination still need to be confirmed. Besides, some studies suggest that the incidence of adverse reactions is associated with dosage $(82,86)$. Whether dosage has an impact on the occurrence of adverse reactions still need to be explored. Meanwhile, interindividual differences in innate immune system should not be disregarded (87).

It is noteworthy that some differences in the safety of vaccines from various platforms have been recognized. An observational study assessed cases of cerebral vein thrombosis and attributed the rates to four COVID-19 vaccines: tozinameran (PfizerBioNTech, mRNA vaccine), CX-024414 (Moderna, mRNA vaccine), ChAdOx1 nCov-19 (AstraZeneca, chimpanzee adenoviral vector vaccine), and AD26.COV2.S (Janssen, adenoviral vector vaccine). It has been found that cases of cerebral vein thrombosis events (with or without thrombocytopenia) were observed for all these four vaccines. Furthermore, compared with adenoviral vaccines, a lower reporting rate of thrombocytopenia and unusual site thrombosis adverse drug reaction was observed for the mRNA vaccine (88). Moreover, a systematic review shows that adverse events associated with serious metabolic, immune system, musculoskeletal, and renal disorders were seen more often with inactivated vaccine recipients; the occurrence of serious gastrointestinal complications and infections was more frequent among viral vector and inactivated vaccine recipients than mRNA vaccines; and serious vessel disorders were observed more in mRNA vaccine recipients (89). Research has found that the common adverse events of ZF2001 (Longcom, a recombinant protein subunit vaccine) were mild or moderate, including injection site pain, swelling, redness, fever, and fatigue. The incidence of fever and fatigue was lower among ZF2001 vaccine recipients than mRNA-based vaccines or adenovirusvectored vaccines (90). Similarly, the first-in-human study of ZyCoV-D (Cadila Healthcare Limited, DNA vaccine) shows that adverse reactions following vaccination including systemic symptoms (headache, fever, fatigue, nausea, vomiting, diarrhea, arthralgia, and muscle pain) and local reactions (injection site pain and pruritus) were mild to moderate in severity (91).

However, these evaluations of the safety profile of COVID-19 vaccines based on different platforms may have several limitations which are related to sample size, comparator group, follow-up time, age, gender, and ethnic group of vaccinated persons. Further exploring the exact associations between vaccination and associated adverse events will lead to a greater and more comprehensive safety assessment of COVID-19 vaccine candidates. Understanding how serious or lifethreatening adverse events could be is helpful to avoid the potential risk of vaccination for patients with related diseases. 
TABLE 1 | The common adverse reactions of mRNA vaccine candidates in clinical trials.

\begin{tabular}{|c|c|c|c|c|c|c|}
\hline $\begin{array}{l}\text { Vaccine } \\
\text { name }\end{array}$ & BNT162b2 $(26,69)$ & $\begin{array}{c}\text { mRNA-1273 } \\
(25,76)\end{array}$ & $\operatorname{CVnCoV}(77,78)$ & ARCT-021 (79) & LNP-nCoVsaRNA (80) & ChulaCov19 (81) \\
\hline Phase & III/IV & IV & III & $\|$ & 1 & I \\
\hline Developers & $\begin{array}{l}\text { BioNTech/Fosun Pharma/ } \\
\text { Pfizer }\end{array}$ & Moderna/NIAID & CureVac AG & Arcturus/Duke-NUS & Imperial College London & $\begin{array}{l}\text { Chulalongkorn } \\
\text { University }\end{array}$ \\
\hline $\begin{array}{l}\text { Age at } \\
\text { vaccination }\end{array}$ & $\geq 16$ years & $\geq 18$ years & 18-60 years & 20-80 years & $18-75$ years & $18-75$ years \\
\hline $\begin{array}{l}\text { Route of } \\
\text { administration }\end{array}$ & $\mathrm{IM}$ & $\mathrm{IM}$ & $\mathrm{IM}$ & $\mathrm{IM}$ & $\mathrm{IM}$ & $\mathrm{IM}$ \\
\hline $\begin{array}{l}\text { Number of } \\
\text { doses }\end{array}$ & 2 & 2 & 2 & 2 & 2 & 2 \\
\hline Duration & $\begin{array}{l}\text { The second injection was } \\
\text { given after } 28 \text { days }\end{array}$ & $\begin{array}{l}\text { The second } \\
\text { injection was } \\
\text { given after } \\
28 \text { days }\end{array}$ & $\begin{array}{l}\text { The second injection was } \\
\text { given after } 28 \text { days }\end{array}$ & - & $\begin{array}{l}\text { The second injection was } \\
\text { given after } 28 \text { days }\end{array}$ & $\begin{array}{l}\text { The second injection } \\
\text { was given after } \\
21 \text { days }\end{array}$ \\
\hline \multirow[t]{2}{*}{$\begin{array}{l}\text { Time of } \\
\text { adverse } \\
\text { reaction }\end{array}$} & Mostly start about 15 min & $\begin{array}{l}\text { Mostly start } \\
\text { about } 15 \mathrm{~h} \\
\text { after } \\
\text { vaccination }\end{array}$ & $\begin{array}{l}\text { Mostly start about } 24 \text { h } \\
\text { after immunization }\end{array}$ & - & - & - \\
\hline & $\begin{array}{l}\text { Right axillary } \\
\text { lymphadenopathy; } \\
\text { paroxysmal ventricular } \\
\text { arrhythmia; right leg } \\
\text { paresthesia }\end{array}$ & $\begin{array}{l}\text { Pneumonia; } \\
\text { immediate } \\
\text { systemic } \\
\text { allergic } \\
\text { reactions }\end{array}$ & $\begin{array}{l}\text { Moderate headache; } \\
\text { injection site pain; } \\
\text { moderate headache; } \\
\text { transient lymphopenia }\end{array}$ & $\begin{array}{l}\text { ARCT-021 was } \\
\text { generally well } \\
\text { tolerated; most } \\
\text { adverse reactions are } \\
\text { mild }\end{array}$ & $\begin{array}{l}\text { Purpura on the skin; } \\
\text { soreness of the arms; } \\
\text { blockage of a vein; small } \\
\text { nerve injury }\end{array}$ & $\begin{array}{l}\text { Pain; tenderness; } \\
\text { induration/swelling; } \\
\text { ulceration; scabs; } \\
\text { hypersensitivity }\end{array}$ \\
\hline $\begin{array}{l}\text { Adverse } \\
\text { reaction }\end{array}$ & $\begin{array}{l}\text { The injection site: mild-to-me } \\
\text { site pain } \\
\text { Respiratory system: cough; } \\
\text { breath } \\
\text { Digestive system: decrease } \\
\text { vomiting; diarrhea } \\
\text { Nervous system: fatigue; letl } \\
\text { headache; dizziness } \\
\text { Systemic reaction: asthenia, } \\
\text { Skin: night sweats, hyperhid }\end{array}$ & $\begin{array}{l}\text { derate injection } \\
\text { hortness of } \\
\text { ppetite; nausea, } \\
\text { argy; paralysis; } \\
\text { malaise } \\
\text { osis }\end{array}$ & & & & \\
\hline
\end{tabular}

Phase: a stage in the development of mRNA vaccine clinical trials.

IM, intramuscular injection.

\section{POSSIBLE STRATEGIES}

Since the outbreak of the COVID-19 pandemic, scientists around the world have been together seeking for a longer-term vaccine solution in order to reduce the risk of SARS-CoV-2 transmission as well as lower COVID-19 morbidity and mortality. Despite significant progress and promising results being gained, the current COVID-19 mRNA vaccine still faces the above intractable challenges. Significantly, the selection of antigen and routes of administration, influencing vaccine efficacy and security, should be taken into account when finding some effective vaccine solution strategies.

\subsection{Antigen Selection}

The core principle of mRNA vaccine is to deliver the mRNA sequence encoding target antigen into the host cell cytoplasm and translate the corresponding antigen by using the host cell machinery, thereby inducing immune responses for the prevention or treatment of disease $(85,92)$. Some features of antigen, such as immunogenicity and specificity, have an impact on the effectiveness of the mRNA vaccine (18). Therefore, the selection of antigens plays an essential role in designing and developing an mRNA vaccine.
As one of the major structural proteins of SARS-CoV-2, the $\mathrm{S}$ (spike) protein plays a crucial role in virus entry and infection and contains several B-cell and T-cell epitopes, which can trigger neutralizing antibodies and immune protection $(93,94)$. Thus, the $\mathrm{S}$ protein is considered a dominant antigen candidate of mRNA vaccine against COVID-19 (95). Both the mRNA-1273 vaccine and BNT162b2 encode the prefusion-stabilized full-length spike protein of SARS-CoV-2 and contribute to prevent and control SARS-CoV-2 and its variant infectiona $(25,96)$. A study (97) established three mRNA vaccine candidates encoding different antigens for COVID-19, showing that only RQ3013VLP (encodes the S, M, and E proteins to form SARS-CoV-2 virus-like particles) induced humoral and T-cell immune responses in mice, for RQ3012-Spike (encodes the full-length wild-type S) and RQ3013-VLP contain the same amount of S mRNA. Notably, RQ3011-RBD ( $2 \mu \mathrm{g}$ RNA/dose, RNA encoding the RBD of the S glycoprotein (residues 331-524) of SARS-CoV-2 with both an $\mathrm{N}$-terminal signal peptide and a C-terminal membrane-anchoring helix) failed to elicit sufficient immunity in mice. However, some improvements may strengthen the immunogenicity of RBD-based mRNA vaccine. Sun et al. (98) found that TF-RBD, an mRNA vaccine based on the trimeric RBD fused to ferritin-formed nanoparticles, induced a stronger 
humoral immunity response and produced RBD-specific antibodies and neutralizing antibodies as well as Th1-biased cellular response in mice, when compared with T-RBD (an mRNA vaccine based on the trimeric RBD). Furthermore, the mRNA vaccine has a high flexibility, because mRNA(s) encoding single or multiple antigens can be co-delivered to enhance and broaden immune responses $(99,100)$. The TF-RBD multivalent vaccine targeting SARS-CoV-2 variants (B.1.1.7 and B.1.351) can elicit a broad spectrum of neutralizing antibodies (98). The TFRBD mRNA vaccine strategy contributes to establish multivalent vaccines against SARS-CoV-2 mutations. Besides the $S$ protein and RBD, other antigens, containing the $\mathrm{S} 1$ subunit and $\mathrm{N}$ terminal domain of the $S$ protein, are used in the studies of immunogenicity as antigen candidates for vaccine against COVID-19 (93, 101, 102). However, whether these antigen candidates are suitable for use in mRNA vaccine for preventing and controlling COVID-19 still needs to be evaluated.

\subsection{Mucosal Vaccination}

So far, most of the vaccine candidates, including mRNA vaccine in clinical phase against COVID-19, can select intramuscular administration (IM) to induce both humoral and cellular immune responses for preventing and controlling COVID-19 (103). However, IM seems to only prevent lower respiratory tract infections but fails to elicit sterilizing immunity in the upper airway, because it induces a strong serum IgG reflex but does not elicit epithelial cell IgA responses $(58,104)$. Generally, the ideal vaccine against SARS-CoV-2 infection through mucosal transmission should be able to elicit not only systemic but also mucosal immune responses $(105,106)$. Recent research suggested that intranasal administration (IN) can elicit high neutralizing antibody generation, mucosal IgA, and T-cell responses to avoid SARS-CoV-2 infection (107). Besides, Du et al. (108) have found that IN shows an excellent profile in inducing mucosal and humoral immune responses in mice, through comparing the immunological potency induced by IN, IM, and ID (intradermal) administration with an RBD-based SARS-CoV-2 vaccine. Furthermore, IN vaccination has some other unique strengths, including non-invasiveness, easy administration, and self-administration, which is a more costeffective and efficient way of administration during the COVID19 pandemic. Interestingly, the self-assembling nanocomplex formulated with cationic cyclodextrin-polyethylenimine $2 \mathrm{k}$ conjugate (CP 2k) is a safe and effective delivery vector for intranasal mRNA vaccine, which can overcome the nasal epithelial barrier and enhance the intranasal and paracellular delivery of mRNA encoding antigen and induce strong mucosal and systemic immune responses (109). Thus, IN administration may be an advantageous immunization route of COVID-19 mRNA vaccine.

\section{CONCLUSION}

Over the past several years, it has become clear that mRNA-based vaccines have promising prophylactic applications. The ongoing
mRNA vaccines against SARS-CoV-2 play an important role in maintaining public health, being the most recent example of critically important advancements in the field of mRNA vaccines. Some potential risks, such as the emergence of novel SARS-CoV-2 variants, increased immune evasion, and serious adverse effects, may have an impact on the effectiveness or promotion of current available COVID-19 mRNA vaccines. It is necessary to further improve mRNA-based vaccines. In addition to choosing the dominant antigen, modifying nucleosides and optimizing sequences are also possible approaches to strengthen protein translation expression and immunogenicity. Vaccines targeting multivalent antigens and combined vaccines may be used to strengthen protective immunity. The mRNA-based vaccine combined with other vaccines will most likely be able to deal with COVID-19 mutations. Nevertheless, this would increase the complexity of the vaccine and any changes to these parameters may have implications on vaccine production and the interaction of vaccines may maximize adverse events after administration. Additional research will need to define the variation trend of SARS-CoV-2 and prepare for long-term coexistence of SARS-CoV-2. Furthermore, the optimal immunization route should be selected to enhance the protective efficiency of mRNA vaccine. Besides intramuscular, intranasal immunization might also be advantageous for inducing immune response. Taken together, prior work involving mRNA-based vaccines, together with current studies of COVID-19 mRNA vaccines, provides evidence for the viability of this novel vaccine modality. There is still a lack of effective data to show the duration of mRNA vaccines under the changing epidemic situation, and a more complete understanding of COVID-19 mRNA vaccine protection still needs to be pursued. This review is focused on the challenges and possible development strategies of mRNA vaccine against SARSCoV-2 and its variants, to provide a theoretical basis for preventing and controlling the COVID-19 pandemic. In summary, efficacy, security, production capacity, and costs need to be carefully evaluated so as to determine whether these strategies for improving mRNA vaccine are feasible and effective.

\section{AUTHOR CONTRIBUTIONS}

All authors listed have made a substantial, direct, and intellectual contribution to the work and approved it for publication.

\section{FUNDING}

This work was supported by the Natural Science Foundation of Hunan Province under Grant No. 2021JJ40455, the Hengyang Science and Technology Planning Project under Grant No. 202002042415, the Hunan Provincial Key Laboratory for Special Pathogens Prevention and Control Foundation under Grant No. 2014-5, and the Hunan Province Cooperative Innovation Center for Molecular Target New Drug Study under Grant No. 2015-351. 


\section{REFERENCES}

1. Wu A, Peng Y, Huang B, Ding X, Wang X, Niu P, et al. Genome Composition and Divergence of the Novel Coronavirus (2019-Ncov) Originating in China. Cell Host Microbe (2020) 273:325-8. doi: 10.1016/ j.chom.2020.02.001

2. Coronaviridae Study Group of the International Committee on Taxonomy of, V. The Species Severe Acute Respiratory Syndrome-Related Coronavirus: Classifying 2019-Ncov and Naming it SARS-CoV-2. Nat Microbiol (2020) 54:536-44. doi: 10.1038/s41564-020-0695-Z

3. Zhu N, Zhang D, Wang W, Li X, Yang B, Song J, et al. A Novel Coronavirus From Patients With Pneumonia in China, 2019. N Engl J Med (2020) 3828:727-33. doi: 10.1056/NEJMoa2001017

4. Sun P, Lu X, Xu C, Sun W, Pan B. Understanding of COVID-19 Based on Current Evidence. J Med Virol (2020) 926:548-51. doi: 10.1002/jmv.25722

5. World Health Organization. WHO Coronavirus (COVID-19) (2021). Available at: https://covid19.who.int/ (Accessed December 23, 2021).

6. Chen $\mathrm{T}, \mathrm{Wu} \mathrm{D}$, Chen H, Yan W, Yang D, Chen G, et al. Clinical Characteristics of 113 Deceased Patients With Coronavirus Disease 2019: Retrospective Study. BMJ (Clin Res Ed) (2020) 368:m1091. doi: 10.1136/ bmj.m1091

7. Gao Z, Xu Y, Sun C, Wang X, Guo Y, Qiu S, et al. A Systematic Review of Asymptomatic Infections With COVID-19. J Microbiol Immunol Infect (2021) 541:12-6. doi: 10.1016/j.jmii.2020.05.001

8. Wang M-Y, Zhao R, Gao L-J, Gao X-F, Wang D-P, Cao J-M. SARS-CoV-2: Structure, Biology, and Structure-Based Therapeutics Development. Front Cell Infect Microbiol (2020) 10:587269. doi: 10.3389/fcimb.2020.587269

9. Parasher A. COVID-19: Current Understanding of its Pathophysiology, Clinical Presentation and Treatment. Postgrad Med J (2021) 971147:312-20. doi: 10.1136/postgradmedj-2020-138577

10. Harrison AG, Lin T, Wang P. Mechanisms of SARS-CoV-2 Transmission and Pathogenesis. Trends Immunol (2020) 4112:1100-15. doi: 10.1016/ j.it.2020.10.004

11. Sommerstein R, Fux CA, Vuichard-Gysin D, Abbas M, Marschall J, Balmelli C, et al. Risk of SARS-CoV-2 Transmission by Aerosols, the Rational Use of Masks, and Protection of Healthcare Workers From COVID-19. Antimicrob Resist Infect Contr (2020) 91:100. doi: 10.1186/s13756-020-00763-0

12. Xu Y, Li X, Zhu B, Liang H, Fang C, Gong Y, et al. Characteristics of Pediatric SARS-CoV-2 Infection and Potential Evidence for Persistent Fecal Viral Shedding. Nat Med (2020) 264:502-5. doi: 10.1038/s41591-020-0817-4

13. Singla R, Mishra A, Joshi R, Jha S, Sharma AR, Upadhyay S, et al. Human Animal Interface of SARS-CoV-2 (COVID-19) Transmission: A Critical Appraisal of Scientific Evidence. Vet Res Commun (2020) 4434:119-30. doi: 10.1007/s11259-020-09781-0

14. Drouin O, Hepburn CM, Farrar DS, Baerg K, Chan K, Cyr C, et al. Characteristics of Children Admitted to Hospital With Acute SARS-CoV2 Infection in Canada in 2020. CMAJ (2021) 19338:E1483-e93. doi: 10.1503/ cmaj. 210053

15. Geng MJ, Wang LP, Ren X, Yu JX, Chang ZR, Zheng CJ, et al. Risk Factors for Developing Severe COVID-19 in China: An Analysis of Disease Surveillance Data. Infect Dis Poverty (2021) 101:48. doi: 10.1186/s40249021-00820-9

16. Scorza FB, Pardi N. New Kids on the Block: RNA-Based Influenza Virus Vaccines. Vaccines (Basel) (2018) 62:20. doi: 10.3390/vaccines6020020

17. Aliprantis AO, Shaw CA, Griffin P, Farinola N, Railkar RA, Cao X, et al. A Phase 1, Randomized, Placebo-Controlled Study to Evaluate the Safety and Immunogenicity of an mRNA-Based RSV Prefusion F Protein Vaccine in Healthy Younger and Older Adults. Hum Vaccin Immunother (2021) 175:1248-61. doi: 10.1080/21645515.2020.1829899

18. Maruggi G, Zhang C, Li J, Ulmer JB, Yu D. mRNA as a Transformative Technology for Vaccine Development to Control Infectious Diseases. Mol Ther (2019) 274:757-72. doi: 10.1016/j.ymthe.2019.01.020

19. Magini D, Giovani C, Mangiavacchi S, Maccari S, Cecchi R, Ulmer JB, et al. Self-Amplifying mRNA Vaccines Expressing Multiple Conserved Influenza Antigens Confer Protection Against Homologous and Heterosubtypic Viral Challenge. PloS One (2016) 118:e0161193. doi: 10.1371/journal.pone. 0161193
20. Alberer M, Gnad-Vogt U, Hong HS, Mehr KT, Backert L, Finak G, et al. Safety and Immunogenicity of a mRNA Rabies Vaccine in Healthy Adults: An Open-Label, non-Randomised, Prospective, First-in-Human Phase 1 Clinical Trial. Lancet (2017) 39010101:1511-20. doi: 10.1016/S0140-6736 (17)31665-3

21. Bahl K, Senn JJ, Yuzhakov O, Bulychev A, Brito LA, Hassett KJ, et al. Preclinical and Clinical Demonstration of Immunogenicity by mRNA Vaccines Against H10N8 and H7N9 Influenza Viruses. Mol Ther (2017) 256:1316-27. doi: 10.1016/j.ymthe.2017.03.035

22. Xu S, Yang K, Li R, Zhang L. mRNA Vaccine Era-Mechanisms, Drug Platform and Clinical Prospection. Int J Mol Sci (2020) 2118:6582. doi: $10.3390 /$ ijms 21186582

23. Zhang C, Maruggi G, Shan H, Li J. Advances in mRNA Vaccines for Infectious Diseases. Front Immunol (2019) 10:594. doi: 10.3389/ fimmu.2019.00594

24. Verbeke R, Lentacker I, De Smedt SC, Dewitte H. The Dawn of mRNA Vaccines: The COVID-19 Case. J Contr Rel (2021) 333:511-20. doi: 10.1016/ j.jconrel.2021.03.043

25. Baden LR, El Sahly HM, Essink B, Kotloff K, Frey S, Novak R, et al. Efficacy and Safety of the mRNA-1273 SARS-CoV-2 Vaccine. N Engl J Med (2021) 3845:403-16. doi: 10.1056/NEJMoa2035389

26. Polack FP, Thomas SJ, Kitchin N, Absalon J, Gurtman A, Lockhart S, et al. Safety and Efficacy of the BNT162b2 mRNA Covid-19 Vaccine. N Engl J Med (2020) 38327:2603-15. doi: 10.1056/NEJMoa2034577

27. Kannan S, Shaik Syed Ali P, Sheeza A. Evolving Biothreat of Variant SARSCoV-2 - Molecular Properties, Virulence and Epidemiology. Eur Rev Med Pharmacol Sci (2021) 2512:4405-12. doi: 10.26355/eurrev_202106 26151

28. Matyasek R, Rehurkova K, Berta Marosiova K, Kovarik A. Mutational Asymmetries in the SARS-CoV-2 Genome May Lead to Increased Hydrophobicity of Virus Proteins. Genes (Basel) (2021) 126:826. doi: 10.3390/genes12060826

29. World Health Organization. Tracking-SARS-CoV-2-Variants (2021). Available at: https://www.who.int/en/activities/tracking-SARS-CoV-2variants/ (Accessed May 31,2021).

30. Plante JA, Mitchell BM, Plante KS, Debbink K, Weaver SC, Menachery VD. The Variant Gambit: COVID-19's Next Move. Cell Host Microbe (2021) 294:508-15. doi: 10.1016/j.chom.2021.02.020

31. Hou YJ, Chiba S, Halfmann P, Ehre C, Kuroda M, Dinnon KH3rd, et al. SARS-CoV-2 D614G Variant Exhibits Efficient Replication Ex Vivo and Transmission in Vivo. Science (2020) 3706523:1464-8. doi: 10.1126/ science.abe 8499

32. Gordon DE, Jang GM, Bouhaddou M, Xu J, Obernier K, White KM, et al. A SARS-CoV-2 Protein Interaction Map Reveals Targets for Drug Repurposing. Nature (2020) 5837816:459-68. doi: 10.1038/s41586-020-2286-9

33. Chia PY, Xiang Ong SW, Chiew CJ, Ang LW, Chavatte J-M, Mak T-M, et al. Virological and Serological Kinetics of SARS-CoV-2 Delta Variant Vaccine Breakthrough Infections: A Multi-Center Cohort Study. Clin Microbiol Infect (2021) S1198-743X(21):00638-8. doi: 10.1016/j.cmi.2021.11.010

34. Kimura I, Kosugi Y, Wu J, Yamasoba D, Butlertanaka EP, Tanaka YL, et al. The SARS-CoV-2 Lambda Variant Exhibits Enhanced Infectivity and Immune Resistance. Cell Rep (2022) 382:110218. doi: 10.1016/ j.celrep.2021.110218

35. Liu H, Wei P, Zhang Q, Aviszus K, Linderberger J, Yang J, et al. The Lambda Variant of SARS-CoV-2 has a Better Chance Than the Delta Variant to Escape Vaccines. bioRxiv (2021) 2021:08.25.457692. doi: 10.1101/ 2021.08.25.457692

36. Baral P, Bhattarai N, Hossen ML, Stebliankin V, Gerstman BS, Narasimhan $\mathrm{G}$, et al. Mutation-Induced Changes in the Receptor-Binding Interface of the SARS-CoV-2 Delta Variant B.1.617.2 and Implications for Immune Evasion. Biochem Biophys Res Commun (2021) 574:14-9. doi: 10.1016/ j.bbrc.2021.08.036

37. Kannan SR, Spratt AN, Cohen AR, Naqvi SH, Chand HS, Quinn TP, et al. Evolutionary Analysis of the Delta and Delta Plus Variants of the SARS-CoV-2 Viruses. J Autoimmun (2021) 124:102715. doi: 10.1016/j.jaut.2021.102715

38. Liu Y, Liu J, Johnson BA, Xia H, Ku Z, Schindewolf C, et al. Delta Spike P681R Mutation Enhances SARS-CoV-2 Fitness Over Alpha Variant. bioRxiv (2021) 2021:08.12.456173. doi: 10.1101/2021.08.12.456173 
39. Weissman D, Alameh MG, de Silva T, Collini P, Hornsby H, Brown R, et al. D614G Spike Mutation Increases SARS CoV-2 Susceptibility to Neutralization. Cell Host Microbe (2021) 291:23-31.e4. doi: 10.1016/ j.chom.2020.11.012

40. Lopez Bernal J, Andrews N, Gower C, Gallagher E, Simmons R, Thelwall S, et al. Effectiveness of Covid-19 Vaccines Against the B.1.617.2 (Delta) Variant. N Engl J Med (2021) 3857:585-94. doi: 10.1056/NEJMoa2108891

41. Fabricius D, Ludwig C, Scholz J, Rode I, Tsamadou C, Jacobsen EM, et al. mRNA Vaccines Enhance Neutralizing Immunity Against SARS-CoV-2 Variants in Convalescent and ChAdOx1-Primed Subjects. Vaccines (Basel) (2021) 98:918. doi: 10.3390/vaccines 9080918

42. Greinacher A, Thiele T, Warkentin TE, Weisser K, Kyrle PA, Eichinger S. Thrombotic Thrombocytopenia After ChAdOx1 Ncov-19 Vaccination. N Engl J Med (2021) 38422:2092-101. doi: 10.1056/NEJMoa2104840

43. Hammerschmidt SI, Bosnjak B, Bernhardt G, Friedrichsen M, Ravens I, Dopfer-Jablonka A, et al. Neutralization of the SARS-CoV-2 Delta Variant After Heterologous and Homologous BNT162b2 or ChAdOx1 Ncov-19 Vaccination. Cell Mol Immunol (2021) 1810:2455-6. doi: 10.1038/s41423021-00755-z

44. Barros-Martins J, Hammerschmidt SI, Cossmann A, Odak I, Stankov MV, Morillas Ramos G, et al. Immune Responses Against SARS-CoV-2 Variants After Heterologous and Homologous ChAdOx1 Ncov-19/BNT162b2 Vaccination. Nat Med (2021) 279:1525-9. doi: 10.1038/s41591-021-01449-9

45. Normark J, Vikstrom L, Gwon YD, Persson IL, Edin A, Bjorsell T, et al. Heterologous ChAdOx1 Ncov-19 and mRNA-1273 Vaccination. N Engl J Med (2021) 38511:1049-51. doi: 10.1056/NEJMc2110716

46. Garcia-Beltran WF, Lam EC, St Denis K, Nitido AD, Garcia ZH, Hauser BM, et al. Multiple SARS-CoV-2 Variants Escape Neutralization by VaccineInduced Humoral Immunity. Cell (2021) 1849:2372-83.e9. doi: 10.1016/ j.cell.2021.03.013

47. Kislaya I, Rodrigues EF, Borges V, Gomes JP, Sousa C, Almeida JP, et al. Delta Variant and mRNA Covid-19 Vaccines Effectiveness: Higher Odds of Vaccine Infection Breakthroughs Authors. medRxiv (2021) 08.14.21262020. doi: 10.1101/2021.08.14.21262020

48. Bian L, Gao F, Zhang J, He Q, Mao Q, Xu M, et al. Effects of SARS-CoV-2 Variants on Vaccine Efficacy and Response Strategies. Expert Rev Vaccines (2021) 204:365-73. doi: 10.1080/14760584.2021.1903879

49. Collier DA, De Marco A, Ferreira IATM, Meng B, Datir R, Walls AC, et al. SARS-CoV-2 B.1.1.7 Sensitivity to mRNA Vaccine-Elicited, Convalescent and Monoclonal Antibodies. MedRxiv Preprint Server Health Sci (2021) 15:2021.01.19.21249840. doi: 10.1101/2021.01.19.21249840

50. Ramesh S, Govindarajulu M, Parise RS, Neel L, Shankar T, Patel S, et al. Emerging SARS-CoV-2 Variants: A Review of Its Mutations, Its Implications and Vaccine Efficacy. Vaccines (2021) 910:1195. doi: 10.3390/ vaccines 9101195

51. Gao Q, Bao L, Mao H, Wang L, Xu K, Yang M, et al. Development of an Inactivated Vaccine Candidate for SARS-CoV-2. Science (2020) 3696499:7781. doi: $10.1126 /$ science.abc1932

52. Yu J, Tostanoski LH, Peter L, Mercado NB, McMahan K, Mahrokhian SH, et al. DNA Vaccine Protection Against SARS-CoV-2 in Rhesus Macaques. Science (2020) 3696505:806-11. doi: 10.1126/science.abc6284

53. Kim J, Eygeris Y, Gupta M, Sahay G. Self-Assembled mRNA Vaccines. $A d v$ Drug Delivery Rev (2021) 170:83-112. doi: 10.1016/j.addr.2020.12.014

54. Pardi N, Hogan MJ, Naradikian MS, Parkhouse K, Cain DW, Jones L, et al. Nucleoside-Modified mRNA Vaccines Induce Potent T Follicular Helper and Germinal Center B Cell Responses. J Exp Med (2018) 2156:1571-88. doi: $10.1084 /$ jem. 20171450

55. Wadman M. The Overlooked Superpower of mRNA Vaccines. Science (2021) 3736554:479. doi: 10.1126/science.373.6554.479

56. Pardi N, Hogan MJ, Weissman D. Recent Advances in mRNA Vaccine Technology. Curr Opin Immunol (2020) 65:14-20. doi: 10.1016/ j.coi.2020.01.008

57. Krienke C, Kolb L, Diken E, Streuber M, Kirchhoff S, Bukur T, et al. A Noninflammatory mRNA Vaccine for Treatment of Experimental Autoimmune Encephalomyelitis. Science (2021) 3716525:145-53. doi: $10.1126 /$ science.aay3638

58. Krammer F. SARS-CoV-2 Vaccines in Development. Nature (2020) 5867830:516-27. doi: 10.1038/s41586-020-2798-3
59. Callow KA, Parry HF, Sergeant M, Tyrrell DA. The Time Course of the Immune Response to Experimental Coronavirus Infection of Man. Epidemiol Infect (1990) 1052:435-46. doi: 10.1017/s0950268800048019

60. Wong SS, Webby RJ. An mRNA Vaccine for Influenza. Nat Biotechnol (2012) 3012:1202-4. doi: 10.1038/nbt.2439

61. Kim YI, Kim SG, Kim SM, Kim EH, Park SJ, Yu KM, et al. Infection and Rapid Transmission of SARS-CoV-2 in Ferrets. Cell Host Microbe (2020) 275:704-9.e2. doi: 10.1016/j.chom.2020.03.023

62. Kuchar E, Załęski A, Wronowski M, Krankowska D, Podsiadły E, Brodaczewska K, et al. Children Were Less Frequently Infected With SARS-CoV-2 Than Adults During 2020 COVID-19 Pandemic in Warsaw, Poland. Eur J Clin Microbiol Infect Dis (2021) 403:541-7. doi: 10.1007/ s10096-020-04038-9

63. Rajapakse N, Dixit D. Human and Novel Coronavirus Infections in Children: A Review. Paediatr Int Child Health (2021) 411:36-55. doi: 10.1080/20469047.2020.1781356

64. World Health Organization. Pandemic Now Driven by Younger Adults (2020). WHO. Available at: https://www.aol.com/article/news/2020/08/18/ coronavirus-pandemic-now-driven-by-younger-adults-who/24593184/ (Accessed Coronavirus [Accessed August 18, 2020]).

65. Wang F, Kream RM, Stefano GB. An Evidence Based Perspective on mRNASARS-CoV-2 Vaccine Development. Med Sci Monit (2020) 26:e924700. doi: $10.12659 / \mathrm{msm} .924700$

66. El Sahly HM, Baden LR, Essink B, Doblecki-Lewis S, Martin JM, Anderson EJ, et al. Efficacy of the mRNA-1273 SARS-CoV-2 Vaccine at Completion of Blinded Phase. N Engl J Med (2021) 38519:1774-85. doi: 10.1056/ NEJMoa2113017

67. Widge AT, Rouphael NG, Jackson LA, Anderson EJ, Roberts PC, Makhene $\mathrm{M}$, et al. Durability of Responses After SARS-CoV-2 mRNA-1273 Vaccination. N Engl J Med (2021) 3841:80-2. doi: 10.1056/NEJMc2032195

68. Collier DA, Ferreira I, Kotagiri P, Datir RP, Lim EY, Touizer E, et al. AgeRelated Immune Response Heterogeneity to SARS-CoV-2 Vaccine BNT162b2. Nature (2021) 5967872:417-22. doi: 10.1038/s41586-02103739-1

69. Vergnes JN. Safety and Efficacy of the BNT162b2 mRNA Covid-19 Vaccine. N Engl J Med (2021) 38416:1577. doi: 10.1056/NEJMc2036242

70. World Health Organization. The Different Types of COVID-19 Vaccines (2021). Available at: https://www.who.int/news-room/feature-stories/ detail/the-race-for-a-COVID-19-vaccine-explained (Accessed January $12,2021)$

71. World Health Organization. COVID-19 Vaccine Tracker and Landscape (2021). Available at: https://www.who.int/publications/m/item/draftlandscape-of-COVID-19-candidate-vaccines (Accessed December 24, 2021).

72. Sherman SM, Smith LE, Sim J, Amlôt R, Cutts M, Dasch H, et al. COVID-19 Vaccination Intention in the UK: Results From the COVID-19 Vaccination Acceptability Study (CoVAccS), a Nationally Representative Cross-Sectional Survey. Hum Vaccin Immunother (2021) 176:1612-21. doi: 10.1080/ 21645515.2020.1846397

73. Dudley MZ, Halsey NA, Omer SB, Orenstein WA, O'Leary ST, Limaye RJ, et al. The State of Vaccine Safety Science: Systematic Reviews of the Evidence. Lancet Infect Dis (2020) 205:e80-e9. doi: 10.1016/s1473-3099 (20)30130-4

74. Kreps S, Prasad S, Brownstein JS, Hswen Y, Garibaldi BT, Zhang B, et al. Factors Associated With US Adults' Likelihood of Accepting COVID-19 Vaccination. JAMA Netw Open (2020) 310:e2025594. doi: 10.1001/jamanetworkopen. 2020.25594

75. Soiza RL, Scicluna C, Thomson EC. Efficacy and Safety of COVID-19 Vaccines in Older People. Age Ageing (2021) 502:279-83. doi: 10.1093/ageing/afaa274

76. Jackson LA, Anderson EJ, Rouphael NG, Roberts PC, Makhene M, Coler RN, et al. An mRNA Vaccine Against SARS-CoV-2 - Preliminary Report. N Engl J Med (2020) 38320:1920-31. doi: 10.1056/NEJMoa2022483

77. Rauch S, Roth N, Schwendt K, Fotin-Mleczek M, Mueller SO, Petsch B. mRNA-Based SARS-CoV-2 Vaccine Candidate $\mathrm{CVnCoV}$ Induces High Levels of Virus-Neutralising Antibodies and Mediates Protection in Rodents. NPJ Vaccines (2021) 61:57. doi: 10.1038/s41541-021-00311-w

78. Rawat K, Kumari P, Saha L. COVID-19 Vaccine: A Recent Update in Pipeline Vaccines, Their Design and Development Strategies. Eur J Pharmacol (2021) 892:173751. doi: 10.1016/j.ejphar.2020.173751 
79. Arcturus Therapeutics. Arcturus Therapeutics Announces Positive Interim ARCT-021 (LUNAR-COV19) Phase 1/2 Study Results for Both Single Shot and Prime-Boost Regimens, and Up to \$220 Million in Additional Financial Commitments From Singapore (2020). Available at: https://ir.arcturusrx. com/news-releases/news-release-details/arcturus-therapeutics-announcespositive-interim-arct-021-lunar (Accessed November 9, 2020).

80. ISRCTN Registry. Clinical Trial to Assess the Safety of a Coronavirus Vaccine in Healthy Men and Women (2020). Available at: https://www.isrctn.com/ ISRCTN17072692 (Accessed May 22, 2020).

81. ClinicalTrials.gov. ChulaCov19 Vaccine in Healthy Adults (2020). Available at: https://clinicaltrials.gov/ct2/show/NCT04566276 (Accessed October 1, 2021).

82. Barda N, Dagan N, Ben-Shlomo Y, Kepten E, Waxman J, Ohana R, et al. Safety of the BNT162b2 mRNA Covid-19 Vaccine in a Nationwide Setting. N Engl J Med (2021) 38512:1078-90. doi: 10.1056/NEJMoa2110475

83. Kounis NG, Koniari I, de Gregorio C, Velissaris D, Petalas K, Brinia A, et al. Allergic Reactions to Current Available COVID-19 Vaccinations: Pathophysiology, Causality, and Therapeutic Considerations. Vaccines (Basel) (2021) 93:221. doi: 10.3390/vaccines9030221

84. Zent O, Arras-Reiter C, Broeker M, Hennig R. Immediate Allergic Reactions After Vaccinations-a Post-Marketing Surveillance Review. Eur J Pediatr (2002) 1611:21-5. doi: 10.1007/s00431-001-0853-0

85. Jackson NAC, Kester KE, Casimiro D, Gurunathan S, DeRosa F. The Promise of mRNA Vaccines: A Biotech and Industrial Perspective. NPJ Vaccines (2020) 5:11. doi: 10.1038/s41541-020-0159-8

86. Chung JY, Thone MN, Kwon YJ. COVID-19 Vaccines: The Status and Perspectives in Delivery Points of View. Adv Drug Deliv Rev (2021) 170:125. doi: 10.1016/j.addr.2020.12.011

87. Hampton LM, Aggarwal R, Evans SJW, Law B. General Determination of Causation Between Covid-19 Vaccines and Possible Adverse Events. Vaccine (2021) 3910:1478-80. doi: 10.1016/j.vaccine.2021.01.057

88. Abbattista M, Martinelli I, Peyvandi F. Comparison of Adverse Drug Reactions Among Four COVID-19 Vaccines in Europe Using the EudraVigilance Database: Thrombosis at Unusual Sites. J Thromb Haemost (2021) 1910:2554-8. doi: 10.1111/jth.15493

89. Fan YJ, Chan KH, Hung IF. Safety and Efficacy of COVID-19 Vaccines: A Systematic Review and Meta-Analysis of Different Vaccines at Phase 3. Vaccines (Basel) (2021) 99:989. doi: 10.3390/vaccines9090989

90. Yang S, Li Y, Dai L, Wang J, He P, Li C, et al. Safety and Immunogenicity of a Recombinant Tandem-Repeat Dimeric RBD-Based Protein Subunit Vaccine (ZF2001) Against COVID-19 in Adults: Two Randomised, Double-Blind, Placebo-Controlled, Phase 1 and 2 Trials. Lancet Infect Dis (2021) 218:110719. doi: 10.1016/s1473-3099(21)00127-4

91. Momin T, Kansagra K, Patel H, Sharma S, Sharma B, Patel J, et al. Safety and Immunogenicity of a DNA SARS-CoV-2 Vaccine (ZyCoV-D): Results of an Open-Label, non-Randomized Phase I Part of Phase I/II Clinical Study by Intradermal Route in Healthy Subjects in India. EClinicalMedicine (2021) 38:101020. doi: 10.1016/j.eclinm.2021.101020

92. Chaudhary N, Weissman D, Whitehead KA. mRNA Vaccines for Infectious Diseases: Principles, Delivery and Clinical Translation. Nat Rev Drug Discov (2021) 2011:817-38. doi: 10.1038/s41573-021-00283-5

93. Arashkia A, Jalilvand S, Mohajel N, Afchangi A, Azadmanesh K, SalehiVaziri M, et al. Severe Acute Respiratory Syndrome-Coronavirus-2 Spike (S) Protein Based Vaccine Candidates: State of the Art and Future Prospects. Rev Med Virol (2021) 313:e2183. doi: 10.1002/rmv.2183

94. Samrat SK, Tharappel AM, Li Z, Li H. Prospect of SARS-CoV-2 Spike Protein: Potential Role in Vaccine and Therapeutic Development. Virus Res (2020) 288:198141. doi: 10.1016/j.virusres.2020.198141

95. Borah P, Deb PK, Al-Shar'i NA, Dahabiyeh LA, Venugopala KN, Singh V, et al. Perspectives on RNA Vaccine Candidates for COVID-19. Front Mol Biosci (2021) 8:635245. doi: 10.3389/fmolb.2021.635245

96. Perry C, Luttwak E, Balaban R, Shefer G, Morales MM, Aharon A, et al. Efficacy of the BNT162b2 mRNA COVID-19 Vaccine in Patients With BCell non-Hodgkin Lymphoma. Blood Adv (2021) 516:3053-61. doi: 10.1182/ bloodadvances.2021005094
97. Lu J, Lu G, Tan S, Xia J, Xiong H, Yu X, et al. A COVID-19 mRNA Vaccine Encoding SARS-CoV-2 Virus-Like Particles Induces a Strong Antiviral-Like Immune Response in Mice. Cell Res (2020) 3010:936-9. doi: 10.1038/s41422020-00392-7

98. Sun W, He L, Zhang H, Tian X, Bai Z, Sun L, et al. The Self-Assembled Nanoparticle-Based Trimeric RBD mRNA Vaccine Elicits Robust and Durable Protective Immunity Against SARS-CoV-2 in Mice. Signal Transduct Target Ther (2021) 61:340. doi: 10.1038/s41392-021-00750-w

99. Zeng C, Zhang C, Walker PG, Dong Y. Formulation and Delivery Technologies for mRNA Vaccines. Curr Top Microbiol Immunol (2020) 2:10.1007/82_2020_217. doi: 10.1007/82_2020_217

100. Vogel AB, Lambert L, Kinnear E, Busse D, Erbar S, Reuter KC, et al. SelfAmplifying RNA Vaccines Give Equivalent Protection Against Influenza to mRNA Vaccines But at Much Lower Doses. Mol Ther (2018) 262:446-55. doi: 10.1016/j.ymthe.2017.11.017

101. Yi C, Sun X, Lin Y, Gu C, Ding L, Lu X, et al. Comprehensive Mapping of Binding Hot Spots of SARS-CoV-2 RBD-Specific Neutralizing Antibodies for Tracking Immune Escape Variants. Genome Med (2021) 131:164. doi: 10.1186/s13073-021-00985-w

102. van Oosten L, Altenburg JJ, Fougeroux C, Geertsema C, van den End F, Evers WAC, et al. Two-Component Nanoparticle Vaccine Displaying Glycosylated Spike S1 Domain Induces Neutralizing Antibody Response Against SARS-CoV-2 Variants. mBio (2021) 125:e0181321. doi: 10.1128/ mBio.01813-21

103. Tiboni M, Casettari L, Illum L. Nasal Vaccination Against SARS-CoV-2: Synergistic or Alternative to Intramuscular Vaccines? Int J Pharm (2021) 603:120686. doi: 10.1016/j.ijpharm.2021.120686

104. Kashte S, Gulbake A, El-Amin Iii SF, Gupta A. COVID-19 Vaccines: Rapid Development, Implications, Challenges and Future Prospects. Hum Cell (2021) 343:711-33. doi: 10.1007/s13577-021-00512-4

105. Borges O, Lebre F, Bento D, Borchard G, Junginger HE. Mucosal Vaccines: Recent Progress in Understanding the Natural Barriers. Pharm Res (2010) 272:211-23. doi: 10.1007/s11095-009-0011-3

106. Mudgal R, Nehul S, Tomar S. Prospects for Mucosal Vaccine: Shutting the Door on SARS-CoV-2. Hum Vaccin Immunother (2020) 1612:2921-31. doi: 10.1080/21645515.2020.1805992

107. Chavda VP, Vora LK, Pandya AK, Patravale VB. Intranasal Vaccines for SARS-CoV-2: From Challenges to Potential in COVID-19 Management. Drug Discov Today (2021) 2611:2619-36. doi: 10.1016/j.drudis.2021.07.021

108. Du Y, Xu Y, Feng J, Hu L, Zhang Y, Zhang B, et al. Intranasal Administration of a Recombinant RBD Vaccine Induced Protective Immunity Against SarsCov-2 In Mouse. Vaccine (2021) 3916:2280-7. doi: 10.1016/ j.vaccine.2021.03.006

109. Li M, Zhao M, Fu Y, Li Y, Gong T, Zhang Z, et al. Enhanced Intranasal Delivery of Mrna Vaccine By Overcoming The Nasal Epithelial Barrier Via Intra- And Paracellular Pathways. J Contr Rel (2016) 228:9-19. doi: 10.1016/ j.jconrel.2016.02.043

Conflict of Interest: The authors declare that the research was conducted in the absence of any commercial or financial relationships that could be construed as a potential conflict of interest.

Publisher's Note: All claims expressed in this article are solely those of the authors and do not necessarily represent those of their affiliated organizations, or those of the publisher, the editors and the reviewers. Any product that may be evaluated in this article, or claim that may be made by its manufacturer, is not guaranteed or endorsed by the publisher.

Copyright (c) $2022 \mathrm{Jin}, \mathrm{Hou}, \mathrm{Li}$, Zheng and Wang. This is an open-access article distributed under the terms of the Creative Commons Attribution License (CC BY). The use, distribution or reproduction in other forums is permitted, provided the original author(s) and the copyright owner(s) are credited and that the original publication in this journal is cited, in accordance with accepted academic practice. No use, distribution or reproduction is permitted which does not comply with these terms. 